\title{
Association between ATM gene polymorphisms, lung cancer susceptibility and radiation-induced pneumonitis: a meta-analysis
}

Zhipeng Yan $^{1+}$, Xiang Tong ${ }^{1+}$, Yao Ma ${ }^{1,2}$, Sitong Liu' ${ }^{1}$, Lingjing Yang ${ }^{1,3}$, Xin Yang ${ }^{1}$, Xue Yang ${ }^{1}$, Min Bai ${ }^{1}$ and Hong Fan ${ }^{1 *}$

\begin{abstract}
Background: Previous studies have suggested that DNA double-strand break (DSB) repair is an important protective pathway after damage. The ataxia telangiectasia mutated (ATM) gene plays an important role in the DNA DSB repair pathway. DNA damage is a major cytotoxic effect that can be caused by radiation, and the ability to repair DNA after damage varies among different tissues. Impaired DNA repair pathways are associated with high sensitivity to radiation exposure. Hence, ATM gene polymorphisms are thought to influence the risk of cancer and radiation-induced pneumonitis (RP) risk in cancer patients treated with radiotherapy. However, the results of previous studies are inconsistent. We therefore conducted this comprehensive meta-analysis.

Methods: A systematic literature search was performed in the PubMed, Embase, China National Knowledge Internet (CNKI) and Wanfang databases to identify studies that investigated the association between the ATM gene polymorphisms and both lung cancer and RP radiotherapy-treated lung cancer (the last search was conducted on Dec.10, 2015). The odds ratio (OR) and $95 \%$ confidence interval (Cl) were used to investigate the strength of these relationships. Funnel plots and Begg's and Egger's tests were conducted to assess the publication bias. All analyses were performed in STATA 13.0 software.

Results: Ten eligible case-control studies (4731 cases and 5142 controls) on lung cancer susceptibility and four (192 cases and 772 controls) on RP risk were included. The results of the overall and subgroup analyses indicated that in the ATM gene, the rs189037 (-111G > A, -4519G > A), rs664677 (44831C > T, 49238C > T) and rs664143 $(131,717 \mathrm{~T}>$ $\mathrm{G})$ polymorphisms were significantly associated with lung cancer susceptibility $(\mathrm{OR}=1.21,95 \% \mathrm{Cl}=1.04-1.39, P=0.01$; $\mathrm{OR}=1.26,95 \% \mathrm{Cl}=1.06-1.49, P=0.01 ; \mathrm{OR}=1.43,95 \% \mathrm{Cl}=1.15-1.78, P<0.01)$. Additionally, the rs 189037 variant was significantly associated with $\mathrm{RP}$ risk $(\mathrm{OR}=1.74,95 \% \mathrm{Cl}=1.02-2.97, P=0.04)$. No publication bias was found in the funnel plots, Begg's tests or Egger's tests.
\end{abstract}

Conclusions: The results indicate that the ATM rs189037, rs664677 and rs664143 gene polymorphisms are risk factors for lung cancer, while the ATM rs189037 variant was significantly associated with RP risk.

Keywords: Ataxia telangiectasia mutated, Polymorphism, Lung cancer, Radiation-induced pneumonitis, Meta-analysis

*Correspondence: fanhongfan@qq.com; fanhongfanscu@sina.cn

${ }^{\dagger}$ Equal contributors

'Department of Respiratory Medicine and Critical Care Medicine, West China Hospital/West China School of Medicine, Sichuan University, Guoxuexiang 37, Chengdu 610041, China

Full list of author information is available at the end of the article 


\section{Background}

Lung cancer is the most common cancer and the most common cause of death from cancer worldwide [1]. Although smoking is a major risk factor for lung cancer, only $15 \%$ of smokers develop lung cancer $[2,3]$, suggesting that different populations are more or less susceptible to carcinogens and that genetic factors probably play an important role in cancer aetiologies [4].

Radiotherapy is an important treatment for cancers. However, $10 \%$ to $20 \%$ of cancer patients who undergo radiotherapy develop severe radiation-induced pneumonitis (RP), which influences their quality of life. Approximately half of patients with RP die [5-7]. RP is a common doselimiting toxicity of radiotherapy [8]. Its risk factors include patient-related factors, such as gender, smoking and pulmonary function, and treatment-related factors, such as the radiation dose and irradiated lung volume, and whether surgery or chemotherapy was performed [9-11]. However, these factors do not sufficiently explain the wide variations observed in susceptibility among patients. Recent studies have shown that variation in individual susceptibility to cancers and RP is affected by gene polymorphisms, especially those affect DNA repair [12].

The ataxia-telangiectasia mutated (ATM) gene is one such DNA repair gene. ATM plays an important role in the repair of DNA damage, especially DNA double-strand breaks (DSBs) [13, 14]. DSBs can lead to genetic information loss, harmful gene variations and chromosomal rearrangements, which can result in the development of cancer [15]. The ATM protein is a phosphoinositide 3-kinase (PI-3 kinases) [13]. Once an exogenous injury, such as ionizing radiation, induces DSBs, the ATM protein is activated via autophosphorylation. It can then phosphorylate dozens of downstream substrates, many of which are key factors in DNA repair, apoptosis, cell cycle arrest and gene regulation $[16,17]$. The affected genes include the checkpoint protein RAD50, cycle checkpoint kinase (CHK2), tumor suppressor P53, breast cancer protein 1 (BRCA1), the repair protein Nijmegen breakage syndrome 1 (NBS1), and the oncogenic protein murine double minute 2 (MDM2) [18, 19]. Polymorphisms in ATM may influence the structure and function of the protein, leading to defects in the activation of cell cycle checkpoints, DNA DSB repair, and cell apoptosis. Additionally, ATM gene mutations may alter the radiosensitivity of cells $[8,20,21]$. The development of cancers and radiation- induced side effects, including pneumonitis, is often linked to these abnormal cells [20, 22].

Previous studies have shown that several ATM gene polymorphisms (e.g., rs664143, rs664677, rs189037, and rs609429) may be associated with susceptibility to lung cancer [23-25], and that others (e.g., rs189037) may be associated with RP risk [26, 27]. However, the results of those studies have been inconsistent, and previous metaanalyses were not comprehensive. Therefore, we conducted this comprehensive meta-analysis to evaluate the association between ATM gene polymorphisms and both susceptibility to lung cancer and the risk of RP in lung cancer patients treated with radiotherapy. To the best of our knowledge, the current study is the most comprehensive analysis of the relationship between susceptibility to lung cancer and ATM gene polymorphisms and the first meta-analysis to evaluate the association between RP risk and ATM gene mutations.

\section{Methods \\ Eligible studies}

We searched the PubMed, Embase, China National Knowledge Internet (CNKI) and Wanfang databases to identify studies that investigated the association between ATM gene polymorphisms and lung cancer as or RP in lung cancer patients treated with radiotherapy (the last search was performed on Dec.10, 2015) using the following search terms: "ATM" and "cancer" or "lung cancer" or "Lung Neoplasms" and "polymorphism" or "variant"; "ATM" and "radiation pneumonia" or "radiation pneumonitis" and "polymorphism" or "variant". The references listed in the resulting articles were also searched to identify additional relevant articles.

The following were the inclusion criteria for studies in our meta-analysis: (1) case-control studies focused on ATM polymorphisms and lung cancer susceptibility or RP risk, (2) data on genotype frequencies were available for both the cases and controls, (3) published in English or Chinese, and (4) the genotype distribution of the control group was in accordance with Hardy-Weinberg equilibrium. The following exclusion criteria were applied: (1) no control group, (2) duplication of a previous study, and (3) no usable data on genotype frequency.

\section{Data extraction}

Two authors independently extracted the data from all eligible publications. The following information was extracted from each relevant study: the first author's name, country of origin, publication year, ethnicity of the study individuals, cancer type, genotyping methods, sample size and genotype frequencies.

\section{Statistical analysis}

All statistical analyses were performed by Stata 13.0. The strength of the association between an ATM polymorphism and lung cancer or RP was measured by odds ratios (ORs) with $95 \%$ confidence intervals (CIs). Heterogeneity was evaluated by the chi-squared $\left(\mathrm{x}^{2}\right)$ and I-squared $\left(\mathrm{I}^{2}\right)$ test. If $P>0.10$ and $\mathrm{I}^{2}<50 \%$, no heterogeneity was detected among the studies, and the OR was calculated by the fixed-effects model. Otherwise, the random-effects model was used. To evaluate ethnicity-specific effects, a subgroup analysis was performed by ethnicity group. 


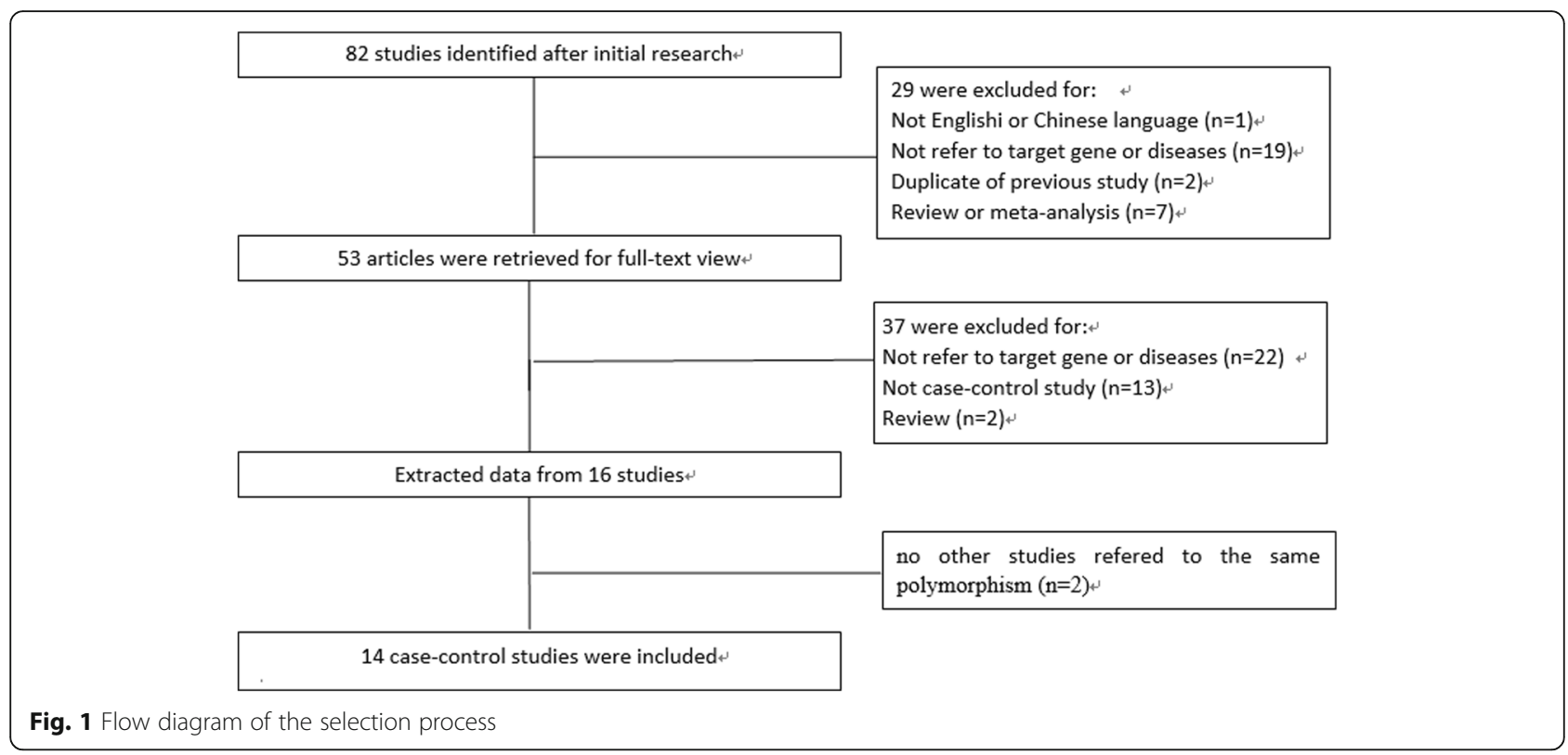

The potential publication bias was assessed by funnel plots, Begg's test and Egger's test.

\section{Results}

\section{Characteristics of the studies}

A total of 82 studies were initially identified from different databases. After reading their titles and abstracts, we excluded 29 reviews or meta-analyses that were not relevant to our study or not published in English or Chinese. After the full-text versions were read, we further excluded 37 studies that did not offer usable data (such as genotype or allele frequency) or other essential information. We extracted information from 16 studies. Two of these studies were excluded because no other studies referred to the same polymorphism (for example, there was only one study on the association between the ATM gene rs373759 and susceptibility to lung cancer), and they were therefore not suitable for inclusion in this meta-analysis. Finally, 14

Table 1 Characteristics of studies included in our meta-analysis

\begin{tabular}{|c|c|c|c|c|c|}
\hline First Author & Year & Country & Ethnicity & Case/control & Method \\
\hline \multicolumn{6}{|c|}{ On lung cancer susceptibility } \\
\hline Xia W [28] & 2010 & China & Asians & $264 / 264$ & TaqMan \\
\hline Bi N [29] & 2014 & China & Asians & $254 / 260$ & PCR-RFLP ${ }^{a}$ \\
\hline Lo YL [25] & 2010 & China & Asians & $730 / 730$ & MassARRAY \\
\hline Shen L [21] & 2014 & China & Asians & $487 / 516$ & TaqMan \\
\hline Hsia TC [30] & 2013 & China & Asians & $358 / 716$ & PCR-RFLP \\
\hline Deng Q [31] & 2010 & China & Asians & $315 / 315$ & $P C R^{b}$ \\
\hline Kim JH [24] & 2006 & Korea & Asians & $616 / 616$ & PCR \\
\hline Liu J [32] & 2014 & China & Asians & $852 / 852$ & TaqMan \\
\hline Yang H [33] & 2007 & USA & Caucasians & $556 / 556$ & TaqMan \\
\hline Landi S [34] & 2007 & Germany & Caucasians & $299 / 317$ & $P C R$ \\
\hline \multicolumn{6}{|l|}{ On RP risk } \\
\hline Zhang L [22] & 2010 & China & Asians & $44 / 209$ & $P C R$ \\
\hline Xiong H [26] & 2012 & China & Asians & $56 / 305$ & PCR-RFLP \\
\hline Xiao Y [27] & 2015 & China & Asians & $48 / 49$ & TaqMan \\
\hline Yang M [35] & 2011 & China & Asians & $44 / 209$ & PCR \\
\hline
\end{tabular}

${ }^{\mathrm{a} P C R}$-RFLP, polymerase chain reaction-restriction fragment length polymorphism 
studies were included in our study (Fig. 1). Among these, 10 studies [21, 24, 25, 28-34] included 4731 cases and 5142 controls, evaluated four single nucleotide polymorphisms (SNPs), and were focused on the association between $A T M$ gene polymorphisms and susceptibility to lung cancer. Four studies [22, 26, 27, 35] included 192 cases and 772 controls, evaluated one SNP, and focused on the association between the risk of RP and ATM gene polymorphisms. Additionally, two studies [33,35] provided only the total number of common genotypes (e.g., AA and AG or AG and GG). Hence, we calculated results for only one model (AA vs. AG + GG). The characteristics of the included studies are summarized in Table 1 and Table 2.

\section{Meta-analysis results}

For the ATM rs189037polymorphism, 3043 cases and 3430 controls from five case- control studies on lung cancer susceptibility were included in the present meta-analysis. The experimental populations in all five studies were Asian. We found that ATM rs189037 polymorphism A allele was associated with an increased risk of lung cancer (AA versus $\mathrm{AG} / \mathrm{GG}, \mathrm{OR}=1.16,95 \% \mathrm{CI}=1.03-1.32$; AA versus $\mathrm{GG}$, $\mathrm{OR}=1.21,95 \% \mathrm{CI}=1.04-1.39$; $\mathrm{A}$ versus $\mathrm{G}, \mathrm{OR}=1.09,95 \%$ $\mathrm{CI}=1.02-1.17$ ) (Fig. 2; Table 3). No publication bias was detected in a funnel plot or Egger's test $(P=0.323)$.

For ATM rs664677, five studies containing 2428 patients and 2439 controls were included. We found that the TT genotype was associated with a significantly higher risk of lung cancer ( $\mathrm{TT}$ versus $\mathrm{TC} / \mathrm{CC}, \mathrm{OR}=1.26,95 \% \mathrm{CI}=1.06$ 1.49), and no significant association was found for this genotype in other genetic models (Fig. 3; Table 3). There was no significant association in the subgroup analysis of Asian populations. No publication bias was detected in a funnel plot or Egger's test $(P=0.565)$.

Table 2 Distributions of ATM gene polymorphisms allele and genotypes in different groups

\begin{tabular}{|c|c|c|c|c|}
\hline rs189037 & AA(case/control) & AG(case/control) & GG(case/control) & $P$ value \\
\hline Lo YL [25] & $145 / 124$ & $345 / 354$ & $238 / 239$ & 0.72 \\
\hline Shen L [21] & $99 / 92$ & $240 / 272$ & $148 / 152$ & 0.12 \\
\hline Hsia TC [30] & $64 / 122$ & $176 / 339$ & $118 / 255$ & 0.61 \\
\hline Kim JH [24] & $105 / 113$ & $316 / 306$ & 190/195 & 0.71 \\
\hline Liu J [32] & $200 / 154$ & $435 / 434$ & $217 / 264$ & 0.29 \\
\hline rs664677 & $\Pi$ (case/control) & TC(case/control) & CC(case/control) & $P$ value \\
\hline Bi N [29] & $40 / 42$ & $120 / 128$ & $94 / 88$ & 0.69 \\
\hline Lo YL [25] & $126 / 104$ & $346 / 356$ & $257 / 268$ & 0.41 \\
\hline Kim JH [24] & $82 / 71$ & $294 / 303$ & $233 / 230$ & 0.06 \\
\hline Landi S [34] & $108 / 85$ & $134 / 170$ & $47 / 54$ & 0.05 \\
\hline Yang H [33] & $445^{\mathrm{a}} / 441^{\mathrm{a}}$ & & $102 / 99$ & \\
\hline rs664143 & AA(case/control) & AG(case/control) & GG(case/control) & $P$ value \\
\hline Xia W [28] & $86 / 68$ & 139/139 & $39 / 55$ & 0.30 \\
\hline Bi N [29] & $71 / 73$ & $137 / 128$ & $46 / 53$ & 0.82 \\
\hline Deng Q [31] & $102 / 86$ & $164 / 158$ & $49 / 69$ & 0.82 \\
\hline Kim JH [24] & $180 / 185$ & $356 / 312$ & $87 / 119$ & 0.54 \\
\hline Yang H [33] & $104 / 95$ & $433^{b} / 441^{b}$ & & \\
\hline rs609429 & CC(case/control) & CG(case/control) & $\mathrm{GG}$ (case/control) & $P$ value \\
\hline Lo YL [25] & $142 / 125$ & $349 / 369$ & $232 / 234$ & 0.32 \\
\hline Landi S [34] & $35 / 52$ & $101 / 113$ & $92 / 70$ & 0.62 \\
\hline Yang H [33] & $103 / 100$ & $436^{c} / 438^{c}$ & & \\
\hline rs189037(RP) & AA(case/control) & AG(case/control) & GG(case/control) & $P$ value \\
\hline Zhang L [22] & $8 / 38$ & $26 / 89$ & $10 / 82$ & 0.12 \\
\hline Xiong H [26] & $24 / 74$ & $22 / 149$ & $10 / 82$ & 0.70 \\
\hline Xiao Y [27] & $11 / 13$ & $22 / 22$ & $15 / 14$ & 0.48 \\
\hline Yang M [35] & $34^{d} / 127^{d}$ & & $10 / 82$ & \\
\hline
\end{tabular}

${ }^{a}$ this figure represents the sum of $T$ and $T C$

$b_{\text {this figure represents the sum of } A G \text { and } G G}$

this figure represents the sum of $C G$ and $G G$

${ }^{d}$ this figure represents the sum of $A A$ and $A G$

$P$ values represent the results of Chi-square tests of Hardy - Weinberg equilibrium 


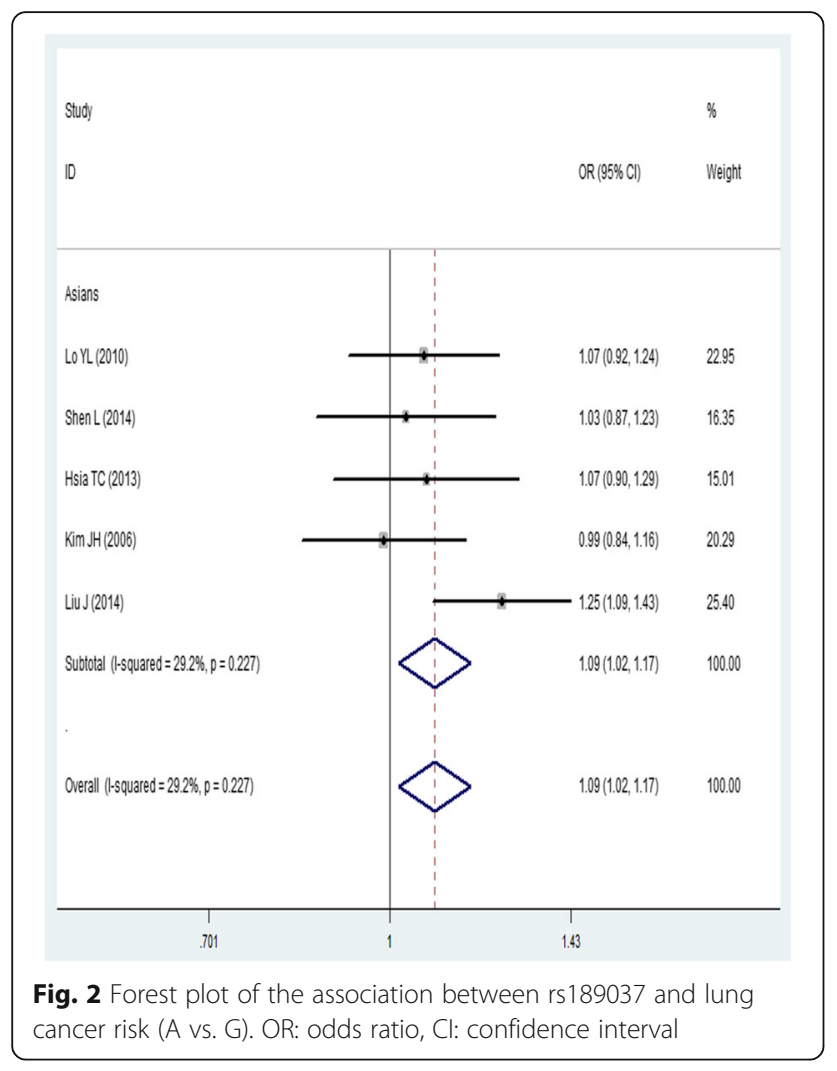

For ATM rs664143, 1983 cases and 1981 controls from five studies were included. We found that the A allele was associated with an increased risk of lung cancer (AA/AG versus $\mathrm{GG}, \mathrm{OR}=1.43,95 \% \mathrm{CI}=1.18-1.73$; AA versus $\mathrm{GG}, \mathrm{OR}=1.43,95 \% \mathrm{CI}=1.15-1.78$; $\mathrm{AG}$ versus $\mathrm{GG}, \mathrm{OR}=1.43,95 \% \mathrm{CI}=1.17-1.75 ; \mathrm{A}$ versus $\mathrm{G}, \mathrm{OR}=$ $1.15,95 \% \mathrm{CI}=1.04-1.28)$. No publication bias was detected in a funnel plot or Egger's test $(P=0.303)$.

For ATM rs609429 (98,158 G > C), we identified 1490 cases and 1501 controls in three studies. We failed to find any significant associations (Fig. 4; Table 3).

With regard for the association between the risk of RP and the ATM rs189037 polymorphism, we identified four studies that contained 192 cases and 772 controls. The results showed that there was a significant association between this SNP and the risk of RP (AA/AG versus GG, $\mathrm{OR}=1.72,95 \% \mathrm{CI}=1.18-2.52$; AA versus $\mathrm{GG}$, $\mathrm{OR}=1.74,95 \% \mathrm{CI}=1.02-2.97)$ (Fig. 5; Table 3). No publication bias was detected in a funnel plot or Egger's test $(P=0.303)$.

\section{Discussion}

In the present meta-analysis, we found that there were significant associations between lung cancer risk and rs189037, rs664677 and rs664143. Additionally, we found that the rs189037 A allele was significantly associated with the risk of RP. Significant heterogeneity was found in two
Table 3 Total results from different comparative genetic models

\begin{tabular}{|c|c|c|c|c|c|}
\hline Gene polymorphisms & OR & $95 \% \mathrm{Cl}$ & $P$ & $I^{2}(\%)$ & Models \\
\hline \multicolumn{6}{|l|}{ On lung cancer risk } \\
\hline \multicolumn{6}{|l|}{ rs189037 } \\
\hline$A A+A G$ vs. GG & 1.10 & $0.99-1.22$ & 0.08 & 8.7 & Fixed \\
\hline$A A$ vs. $A G+G G$ & 1.16 & $1.03-1.32$ & 0.02 & 19.9 & Fixed \\
\hline AA vs. GG & 1.21 & $1.04-1.39$ & 0.01 & 32.7 & Fixed \\
\hline AG vs. GG & 1.06 & $0.95-1.19$ & 0.30 & 0 & Fixed \\
\hline A vs. G & 1.09 & $1.02-1.17$ & 0.01 & 29.2 & Fixed \\
\hline \multicolumn{6}{|l|}{ rs664677 } \\
\hline$T+\mathrm{TC}$ vs. CC & 1.01 & $0.89-1.14$ & 0.88 & 0 & Fixed \\
\hline TT vs. TC + CC & 1.26 & $1.06-1.49$ & 0.01 & 1.1 & Fixed \\
\hline TT vs. CC & 1.20 & $0.98-1.46$ & 0.08 & 0.0 & Fixed \\
\hline TC vs. CC & 0.96 & $0.83-1.11$ & 0.60 & 0.0 & Fixed \\
\hline T vs. C & 1.08 & $0.98-1.18$ & 0.12 & 9.7 & Fixed \\
\hline \multicolumn{6}{|l|}{ rs664143 } \\
\hline$A A+A G$ vs. GG & 1.43 & $1.18-1.73$ & 0 & 0 & Fixed \\
\hline$A A$ vs. $A G+G G$ & 1.10 & $0.95-1.27$ & 0.20 & 0 & Fixed \\
\hline AA vs. GG & 1.43 & $1.15-1.78$ & $<0.01$ & 0 & Fixed \\
\hline AG vs. GG & 1.43 & $1.17-1.75$ & $<0.01$ & 0 & Fixed \\
\hline A vs. G & 1.15 & $1.04-1.28$ & $<0.01$ & 0 & Fixed \\
\hline \multicolumn{6}{|l|}{ rs609429 } \\
\hline$A A$ vs. $A G+G G$ & 0.97 & $0.72-1.32$ & 0.85 & 59.3 & Random \\
\hline \multicolumn{6}{|l|}{ On RP risk } \\
\hline \multicolumn{6}{|l|}{ rs189037 } \\
\hline$A A+A G$ vs. GG & 1.72 & $1.18-2.52$ & $<0.01$ & 2.6 & Fixed \\
\hline$A A$ vs. $A G+G G$ & 1.34 & $0.67-2.66$ & 0.57 & 57.4 & Random \\
\hline AA vs. GG & 1.74 & $1.02-2.97$ & 0.04 & 35.8 & Fixed \\
\hline AG vs. GG & 1.48 & $0.92-2.37$ & 0.11 & 23.2 & Fixed \\
\hline A vs. G & 0.57 & $0.18-1.77$ & 0.33 & 97.5 & Random \\
\hline
\end{tabular}

of the genetic models used to evaluate the risk of RP. This may be because different diagnostic standards were used in different studies. Fortunately, the genetic models identified in our study that did produce significant associations results showed no significant heterogeneity. No significant publication bias was found in polymorphisms that were covered by at least five studies.

ATM rs189037 is located in the 5'UTR of the promoter region of the ATM gene [36]. This SNP can bind to the activator protein $2 \alpha$ (AP-2 $\alpha$ ), which represses ATM transcription, and different genotypes have different affinities for this transcription factor [37]. As some studies have suggested, the AA genotype of ATM rs189037 increases the risk of oral [38] and breast cancer [39]. Furthermore, this mutation may be associated with the risk of thyroid carcinoma [40]. ATM rs664143 is located in the protein binding motifs that serve as binding sites for intronic splicing enhancers or repressors, suggesting the possibility 

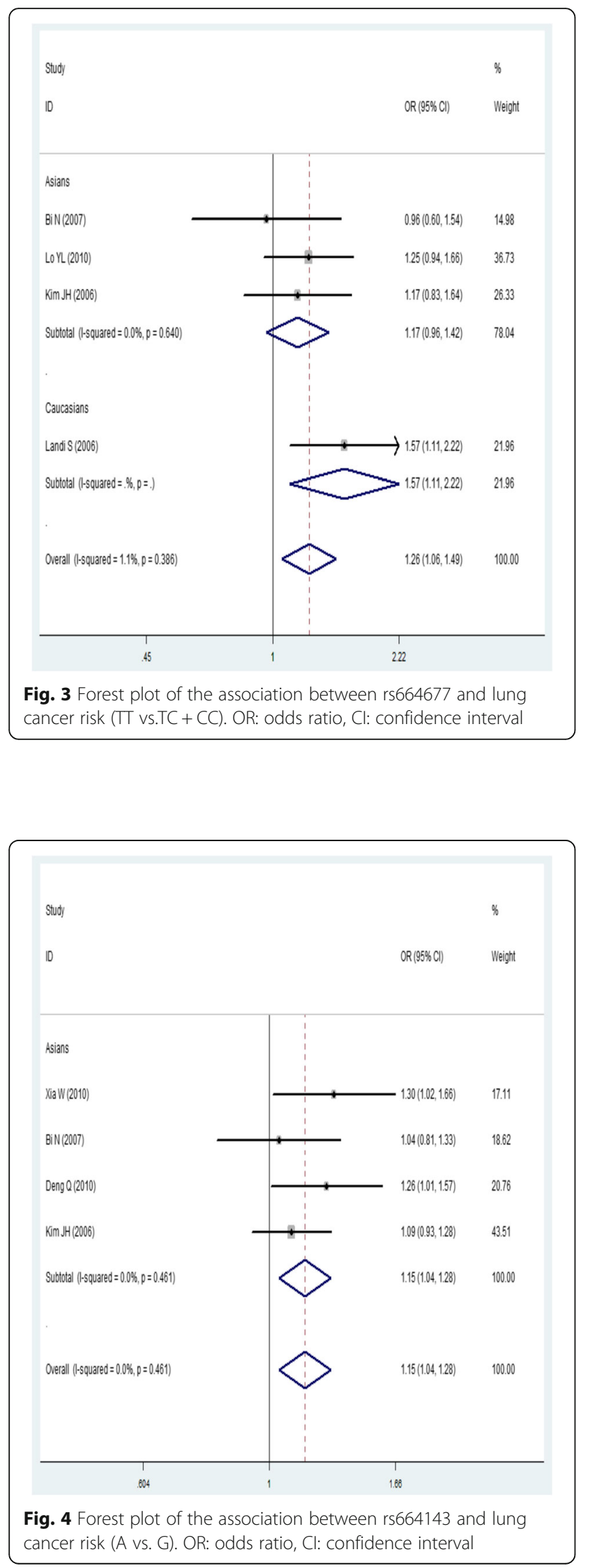

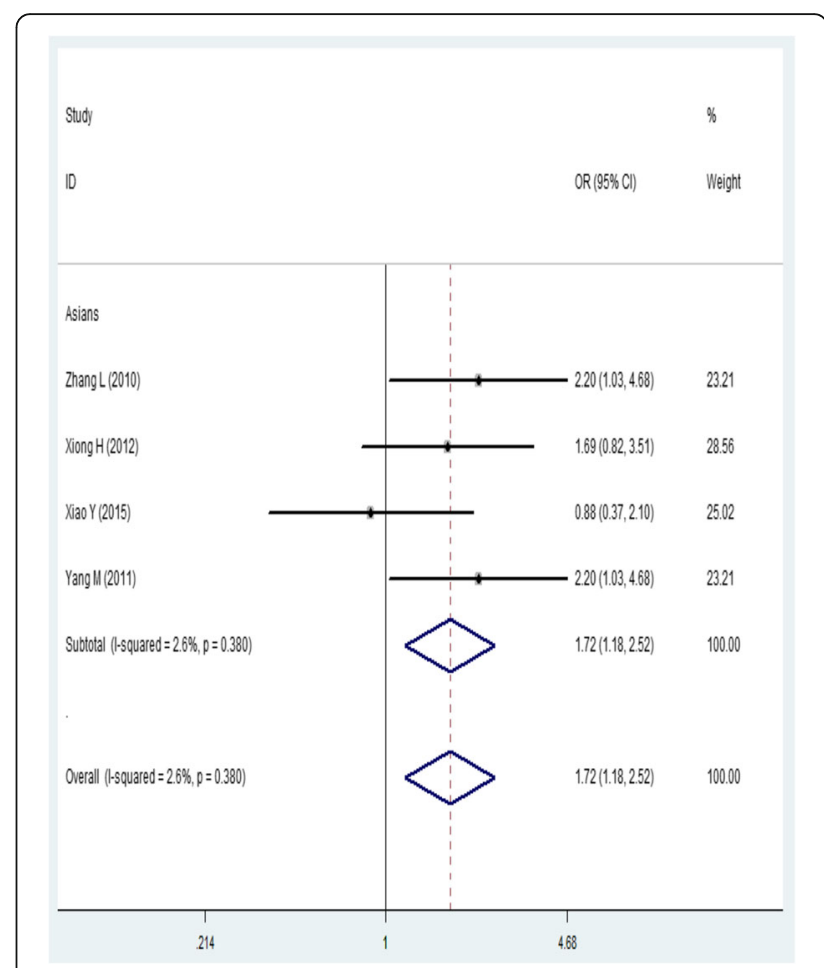

Fig. 5 Forest plot of the association between rs189037 and RP risk (AA + AG vs. GG). OR: odds ratio, Cl: confidence interval that this site may be involved in the exon 61 splicing process and that it may cause inaccurate splicing [24]. The precise roles of rs664677 and rs609429 remain unclear [41]. The former loci may participate in regulating RNA splicing and maintaining RNA stability [41]. A study performed in Korea showed that the rs664677 CC genotype might be associated with a higher risk of breast cancer [42]. However, rs664677 was not associated with either papillary thyroid carcinoma $[43,44]$ or pancreatic cancer [45]. Other studies failed to find a significant association between this loci and the risk of cancers, such as breast cancer $[46,47]$. DNA repair pathways are activated after DNA damage, especially DNA DSBs [20]. Individuals with impaired DNA repair pathways have high sensitivity to radiation exposure and therefore a higher risk of lung cancer and RP $[8,20]$. Previous studies have suggested that the ATM gene plays a critical role in DNA damage repair and thereby affects the risk of lung cancer and RP. We performed this meta-analysis because the results of previous studies were inconclusive.

Several limitations of the current analysis should be mentioned. First, we failed to conduct a subgroup analysis to evaluate the effects of other factors, such as gender, smoking status or histological subtypes, because insufficient data was available. Second, we included only articles published in either English or Chinese, resulting in potential 
publication bias, despite the fact that the Egger's test and funnel plots showed that there was no publication bias. Despite these limitations, the likelihood of bias was minimized throughout the process because we used a detailed protocol that included study identification, data selection and the statistical analysis, and we controlled publication bias. Therefore, we believe that our results are reliable. Additionally, most polymorphisms and studies of the ATM gene are included in this study. It is also the first metaanalysis to evaluate the association between ATM gene polymorphisms and the risk of RP.

\section{Conclusions}

In conclusion, in this meta-analysis, we showed that the ATM rs189037 polymorphism is significantly associated with lung cancer and the risk of RP after radiotherapy. The ATM rs664677 and ATM rs664143 polymorphisms were significantly associated with lung cancer susceptibility, while rs609429 was not. More well-designed studies that include larger sample sizes should be performed in the future to further evaluate the association between the ATM gene and cancers.

\section{Abbreviations}

ATM: Ataxia telangiectasia mutated; BRCA1: Breast cancer protein 1; CHK2: Cycle checkpoint kinase 2; Cl: Confidence intervals; CNKl: China National Knowledge Infrastructure; DNA: Deoxyribonucleic acid; DSB: Double-strand breaks; MDM2: Murine double minute 2; NBS1: Nijmegen breakage syndrome; OR: Odds ratios; RNA: Ribonucleic acid; RP: Radiation-induced pneumonitis; SNP: Single nucleotide polymorphism

\section{Acknowledgements}

Not applicable.

\section{Funding}

This work was supported by the Department of Science and Technology of Sichuan Province (Grant No.2016FZ0082).

\section{Availability of data and materials}

The datasets used and/or analysed during the current study are available from the corresponding author on reasonable request.

\section{Authors' contributions}

HF designed the study, provided resources, coordinated the study and directed its implementation. $Z Y$ and $X T$ searched the publications, extracted the data and wrote the manuscript. ZY, YM, SL, LY, XY and MB were responsible for data synthesis. $X Y$ wrote the introduction. All authors have read and approved the final manuscript.

\section{Ethics approval and consent to participate}

Not applicable.

\section{Consent for publication}

Not applicable.

\section{Competing interests}

The authors declare that they have no competing interests.

\section{Publisher's Note}

Springer Nature remains neutral with regard to jurisdictional claims in published maps and institutional affiliations.

\section{Author details}

'Department of Respiratory Medicine and Critical Care Medicine, West China Hospital/West China School of Medicine, Sichuan University, Guoxuexiang 37 Chengdu 610041, China. ${ }^{2}$ Department of Internal Medicine, No.4 West China Teaching Hospital, Sichuan University, Renming South Road 3rd Section 18, Chengdu 610041, China. ${ }^{3}$ Department of Respiration, East Branch, Sichuan Provincial People's Hospital, Sichuan Academy of Medical Science, No. 585 Honghe North Road, Chengdu 610110, China.

Received: 19 September 2016 Accepted: 7 December 2017

Published online: 15 December 2017

\section{References}

1. Ferlay J, Shin HR, Bray F, Forman D, Mathers C, Parkin DM. Estimates of worldwide burden of cancer in 2008: GLOBOCAN 2008. Int J Cancer. 2010;127(12):2893-917.

2. Shields PG. Molecular epidemiology of smoking and lung cancer. Oncogene. 2002;21(45):6870-6.

3. Shields PG, Harris CC. Cancer risk and low-penetrance susceptibility genes in gene-environment interactions. J Clin Oncol. 2000;18(11):2309-15.

4. Hornhardt S, Rossler U, Sauter W, Rosenberger A, Illig T, Bickeboller H, Wichmann HE, Gomolka M. Genetic factors in individual radiation sensitivity. DNA repair. 2014;16:54-65.

5. Roach M 3rd, Gandara DR, Yuo HS, Swift PS, Kroll S, Shrieve DC, Wara WM Margolis L, Phillips TL. Radiation pneumonitis following combined modality therapy for lung cancer: analysis of prognostic factors. J Clin Oncol. 1995;13(10):2606-12.

6. Inoue A, Kunitoh H, Sekine I, Sumi M, Tokuuye K, Saijo N. Radiation pneumonitis in lung cancer patients: a retrospective study of risk factors and the long-term prognosis. Int J Radiat Oncol Biol Phys. 2001;49(3):649-55.

7. Wang JY, Chen KY, Wang JT, Chen JH, Lin JW, Wang HC, Lee LN, Yang PC. Outcome and prognostic factors for patients with non-small-cell lung cancer and severe radiation pneumonitis. Int J Radiat Oncol Biol Phys. 2002;54(3):735-41.

8. Huang $Q$, Xie F, Ouyang X, Predictive SNP. For radiation-induced damage in lung cancer patients with radiotherapy: a potential strategy to individualize treatment. Int J Biol Markers. 2015:30(1):e1-11.

9. Zhang XJ, Sun JG, Sun J, Ming H, Wang XX, Wu L, Chen ZT. Prediction of radiation pneumonitis in lung cancer patients: a systematic review. J Cancer Res Clin Oncol. 2012;138(12):2103-16.

10. Giuliani ME, Lindsay PE, Kwan JY, Sun A, Bezjak A, Le LW, Brade A, Cho J, Leighl $N B$, Shepherd FA, et al. Correlation of dosimetric and clinical factors with the development of esophagitis and radiation pneumonitis in patients with limited-stage small-cell lung carcinoma. Clin Lung Cancer. 2015;16(3):216-20.

11. Dang J, Li G, Zang S, Zhang S, Yao L. Risk and predictors for early radiation pneumonitis in patients with stage III non-small cell lung cancer treated with concurrent or sequential chemoradiotherapy. Radiat Oncol. 2014;9:172.

12. Guo CX, Wang J, Huang LH, Li JG, Chen X. Impact of single-nucleotide polymorphisms on radiation pneumonitis in cancer patients. Mol Clin Oncol. 2016;4(1):3-10.

13. Kurz EU, Lees-Miller SPDNA. Damage-induced activation of ATM and ATMdependent signaling pathways. DNA repair. 2004;3(8-9):889-900.

14. Petrini $J H$, Stracker TH. The cellular response to DNA double-strand breaks: defining the sensors and mediators. Trends Cell Biol. 2003;13(9):458-62.

15. Weber AM, Ryan AJ. ATM and ATR as therapeutic targets in cancer. Pharmacol Ther. 2015;149:124-38.

16. Banin S, Moyal L, Shieh S, Taya Y, Anderson CW, Chessa L, Smorodinsky NI, Prives $C$, Reiss $Y$, Shiloh Y, et al. Enhanced phosphorylation of p53 by ATM in response to DNA damage. Science. 1998:281(5383):1674-7.

17. Canman CE, Lim DS, Cimprich KA, Taya Y, Tamai K, Sakaguchi K, Appella E, Kastan MB, Siliciano JD. Activation of the ATM kinase by ionizing radiation and phosphorylation of p53. Science. 1998;281(5383):1677-9.

18. Shiloh YATM. related protein kinases: safeguarding genome integrity. Nat Rev Cancer. 2003:3(3):155-68.

19. Rotman G, Shiloh YATM. From gene to function. Hum Mol Genet. 1998:7(10):1555-63.

20. Lavin MF, Kozlov S. ATM activation and DNA damage response. Cell Cycle 2007:6(8):931-42.

21. Shen $L$, Yin Z, Wu W, Ren Y, Li X, Zhou B. Single nucleotide polymorphism in ATM gene, cooking oil fumes and lung adenocarcinoma susceptibility in Chinese female non-smokers: a case-control study. PLoS One. 2014;9(5):e96911. 
22. Zhang $L$, Yang $M$, Bi N, Fang $M$, Sun $T$, Ji W, Tan W, Zhao L, Yu D, Lin D, et al. ATM polymorphisms are associated with risk of radiation-induced pneumonitis. Int J Radiat Oncol Biol Phys. 2010;77(5):1360-8.

23. Shen L, Yin ZH, Wan Y, Zhang Y, Li K, Zhou BS. Association between ATM polymorphisms and cancer risk: a meta-analysis. Mol Biol Rep. 2012;39(5): 5719-25.

24. Kim JH, Kim H, Lee KY, Choe KH, Ryu JS, Yoon HI, Sung SW, Yoo KY, Hong YC. Genetic polymorphisms of ataxia telangiectasia mutated affect lung cancer risk. Hum Mol Genet. 2006;15(7):1181-6.

25. Lo YL, Hsiao CF, Jou YS, Chang GC, Tsai YH, WC S, Chen YM, Huang MS Chen $\mathrm{HL}$, Yang PC, et al. ATM polymorphisms and risk of lung cancer among never smokers. Lung Cancer. 2010;69(2):148-54.

26. Xiong H, Liao Z, Liu Z, Xu T, Wang Q, Liu H, Komaki R, Gomez D, Wang LE, Wei QATM. Polymorphisms predict severe radiation pneumonitis in patients with non-small cell lung cancer treated with definitive radiation therapy. Int J Radiat Oncol Biol Phys. 2013;85(4):1066-73.

27. Xiao Y, Yuan X, Qiu H, Li Q. Single-nucleotide polymorphisms of TGFbeta1 and ATM associated with radiation-induced pneumonitis: a prospective cohort study of thoracic cancer patients in China. Int J Clin Exp Med. 2015;8(9):16403-13.

28. Xia WJ, Su D, Liu P, Ma SL, Jiang ZM, Zhang YM. Single nucleotide polymorphism in ATM and non-small cell lung cancer susceptibility (Chinese). CHINA. Oncology. 2010;20(2):121-4.

29. Bi N. Association between ATM Haplotypes and Susceptibility of Small Cell Lung Cancer,as well as Response to Platinum-Based Chemotherapy (Chinese). Chinese Academy of Medical Sciences \& Peking Union Medical College 2007.

30. Hsia TC, Tsai CW, Liang SJ, Chang WS, Lin LY, Chen WC, CY T, Tsai CH, Bau DT. Effects of ataxia telangiectasia mutated (ATM) genotypes and smoking habits on lung cancer risk in Taiwan. Anticancer Res. 2013;33(9):4067-71.

31. Deng Q, Sheng L, Su D, Zhang L, Liu P, Lu K, Ma S. Genetic polymorphisms in ATM, ERCC1, APE1 and ASPP genes and lung cancer risk in a population of southeast China. Med Oncol. 2011;28(3):667-72.

32. Liu J, Wang X, Ren Y, Li X, Zhang X, Zhou B. Effect of single nucleotide polymorphism Rs189037 in ATM gene on risk of lung cancer in Chinese: a case-control study. PLoS One. 2014;9(12):e115845.

33. Yang H, Spitz MR, Stewart DJ, Lu C, Gorlov IP, ATM WX. Sequence variants associate with susceptibility to non-small cell lung cancer. Int J Cancer. 2007;121(10):2254-9.

34. Landi S, Gemignani F, Canzian F, Gaborieau V, Barale R, Landi D, SzeszeniaDabrowska N, Zaridze D, Lissowska J, Rudnai P, et al. DNA repair and cell cycle control genes and the risk of young-onset lung cancer. Cancer Res. 2006;66(22):11062-9.

35. Yang M, Zhang L, Bi N, Ji W, Tan W, Zhao L, Yu D, Wu C, Wang L, Lin D. Association of P53 and ATM polymorphisms with risk of radiation-induced pneumonitis in lung cancer patients treated with radiotherapy. Int J Radiat Oncol Biol Phys. 2011;79(5):1402-7.

36. Gu Y, Liu X, Yu Y, Shi J, Ai L, Sun H, Kanu JS, Wang C, Liu Y. Association of ATM Gene Polymorphism with PTC Metastasis in Female Patients. Int J Endocrinol. 2014;2014:370825.

37. Chen T, Dong B, Lu Z, Tian B, Zhang J, Zhou J, Wu H, Zhang Y, Wu J, Lin P, et al. A functional single nucleotide polymorphism in promoter of ATM is associated with longevity. Mech Ageing Dev. 2010;131(10):636-40.

38. Bau DT, Chang CH, Tsai MH, Chiu CF, Tsou YA, Wang RF, Tsai CW, Tsai RY. Association between DNA repair gene ATM polymorphisms and oral cancer susceptibility. Laryngoscope. 2010;120(12):2417-22.

39. Wang HC, Chang WS, Tsai RY, Tsai CW, Liu LC, CH S, Cheng HN, Tsou YA, Sun SS, Lin CC, et al. Association between ataxia telangiectasia mutated gene polymorphisms and breast cancer in Taiwanese females. Anticancer Res. 2010;30(12):5217-21.

40. Xu L, Morari EC, Wei Q, Sturgis EM, Ward LS. Functional variations in the ATM gene and susceptibility to differentiated thyroid carcinoma. J Clin Endocrinol Metab. 2012;97(6):1913-21.

41. Li D, Frazier M, Evans DB, Hess KR, Crane CH, Jiao L, Abbruzzese JL. Single nucleotide polymorphisms of RecQ1, RAD54L, and ATM genes are associated with reduced survival of pancreatic cancer. J Clin Oncol. 2006;24(11):1720-8.

42. Lee KM, Choi JY, Park SK, Chung HW, Ahn B, Yoo KY, Han W, Noh DY, Ahn SH, Kim H, Wei Q, Kang D. Genetic polymorphisms of ataxia telangiectasia mutated and breast cancer risk. Cancer Epidemiol Biomarkers Prev. 2005; 14(4):821-5.
43. Song CM, Kwon TK, Park BL, Ji YB, Tae K. Single nucleotide polymorphisms of ataxia telangiectasia mutated and the risk of papillary thyroid carcinoma. Environ Mol Mutagen. 2015;56(1):70-6.

44. Akulevich NM, Saenko VA, Rogounovitch TI, Drozd VM, Lushnikov EF, Ivanov VK, Mitsutake N, Kominami R, Yamashita S. Polymorphisms of DNA damage response genes in radiation-related and sporadic papillary thyroid carcinoma. Endocr Relat Cancer. 2009;16(2):491-503.

45. Li D, Suzuki H, Liu B, Morris J, Liu J, Okazaki T, Li Y, Chang P, Abbruzzese JLDNA. Repair gene polymorphisms and risk of pancreatic cancer. Clin Cancer Res. 2009;15(2):740-6.

46. Lee SA, Lee KM, Lee SJ, Yoo KY, Park SK, Noh DY, Ahn SH, Kang D. Antioxidant vitamins intake, ataxia telangiectasia mutated (ATM) genetic polymorphisms, and breast cancer risk. Nutr Cancer. 2010;62(8):1087-94.

47. Ye C, Dai Q, Lu W, Cai Q, Zheng Y, Shu XO, Gu K, Gao YT, Zheng W. Twostage case-control study of common ATM gene variants in relation to breast cancer risk. Breast Cancer Res Treat. 2007;106(1):121-6.

\section{Submit your next manuscript to BioMed Central and we will help you at every step:}

- We accept pre-submission inquiries

- Our selector tool helps you to find the most relevant journal

- We provide round the clock customer support

- Convenient online submission

- Thorough peer review

- Inclusion in PubMed and all major indexing services

- Maximum visibility for your research

Submit your manuscript at www.biomedcentral.com/submit
C Biomed Central 